\title{
La antropofagia como actitud: en las vanguardias, en el tropicalismo y en la literatura periférica
}

\author{
Cannibalism as an Attitude: The Avant-garde in \\ Literature Tropicalia and Peripheral
}

A antropofagia como atitude: nas vanguardas, no

Tropicalismo e na literatura periférica

\section{Victor Hugo Adler Pereira}

UNIVERSIDADE DO ESTADO DO RIO DE JANEIRO (UERJ)

Profesor de la Universidade do Estado do Rio de Janeiro (UERJ).

Doctor en Letras Vernáculas de la misma institución. Dentro de sus principales publicaciones se encuentran: Nelson Rodrigues, o freudismo e o carnaval nos teatros modernos (7Letras, 2012), Nelson Rodrigues e a obs-cena contemporânea (Eduerj, 1999), A musa carrancuda: teatro e poder no Estado Novo (Fundação Getúlio Vargas, 1998). Correo electrónico: vhap@uol.com.br

\footnotetext{
Artículo de reflexión

El artículo se deriva de una investigación más amplia, sobre las peculiaridades del proceso de modernización en Brasil, en el marco del proyecto intitulado "A literatura e os legados da modernização excludente", apoyado por una beca del Programa Prociencia de la Fundação de Amparo à Pesquisa do Estado do Rio de faneiro FAPERJ y la UERJ y una Beca de Produtividad en Investigación del CNPq. Este artículo se basa en la conferencia "A antropofagia periférica e outras revisões do cosmopolitismo modernista", realizada en el ciclo "Depois do Modernismo", PUC-Rio, 2012. Traducción de Maria Cândida Ferreira de Almeida y Santiago Fernando Vásquez Morales (estudiante de Literatura de la Universidad de los Andes, Bogotá; correo electrónico: sf.vasquez279@uniandes.edu.co). Documento accesible en línea desde la siguiente dirección: http://revistas.javeriana.edu.co
} 


\section{Resumen}

Este artículo presenta un análisis de la configuración de la antropofagia como metáfora fundamental en el desarrollo de movimientos políticos y artísticos en el siglo XX brasileño. Con base en la presentación realizada en el "Manifiesto antropófago" por Oswald de Andrade, se analizan diálogos e influencias, así como matices que surgieron en representaciones tanto literarias como musicales. Así mismo, el artículo evidencia el papel de la antropofagia dentro de la búsqueda de una identidad nacional inmersa en procesos que confrontaron corrientes de pensamiento divergentes.

Palabras clave: modernismo, antropofagia, literatura periférica.

Palabras descriptor:

Modernidad, antropofagia, identidad nacional, siglo XX, Brasil.

\section{Abstract}

This paper presents an analysis of the configuration of cannibalism as a metaphor central to the development of political and artistic movements in the twentieth century of Brazil. Based on the presentation made in the "Manifesto cannibal" by Oswald de Andrade are analyzed dialogues and influences and nuances that emerged in both literary and musical performances. Also the paper highlights the role of cannibalism in the search for a national identity immersed in processes, which confronted divergent perspectives of thinking.

Keywords: modernism, anthropophagy, minority literature. Keywords plus: Modernity, cannibalism, national identity, XX century, Brazil.

\section{Resumo}

Este trabalho apresenta uma análise da configuração do canibalismo como metáfora fundamental no desenvolvimento político e artístico dos

movimentos brasileiros do século XX. Com base na apresentação feita em "Comer manifesto", de Oswald de Andrade, diálogos e influências são discutidos, bem como nuances que surgiram em ambas as performances literárias e musicais. Além disso, o documento destaca o papel de canibalismo na busca de uma identidade nacional incorporado nos processos atuais que confrontam o pensamento divergente.

Palavras-chaves: modernismo, canibalismo, literatura periférica. Palavras-chave descritores: Modernidade, canibalismo, identidade nacional, século XX, Brasil.

RECIBIDO: 7 DE ABRIL DE 2013. EVALUADO: 19 DE MAYO DE 2013. ACEPTADO: 19 DE MAYO DE 2013.

\section{Cómo citar este artículo:}

Pereira, Victor Hugo Adler. "La antropofagia como actitud: en las vanguardias, en el

tropicalismo y en la literatura periférica". Cuadernos de Literatura 18.35 (2014): 132-149. 
Guando Sérgio VAz, poeta de la periferia paulista, retoma la metáfora de la antropofagia para posicionarse frente a los problemas relativos a la producción cultural, estimula una reevaluación de los sentidos que esta alcanzó en la trayectoria de Oswald de Andrade, y sus repercusiones en debates desarrollados por artistas e intelectuales en los años sesenta en Brasil.

La metáfora, presentada de modo irreverente en 1928 por Oswald de Andrade con el "Manifiesto antropófago", tradujo un conjunto de preocupaciones y actitudes de ese poeta e intelectual en diferentes momentos de la vida que, conforme subraya el crítico Benedito Nunes (51-57), no estaban ausentes ni cuando, motivado por su adhesión al marxismo, hizo autocrítica de su participación en el movimiento modernista.

El empleo de tal metáfora para tratar de modo irreverente y demoledor la tradición cultural europea no era original. Franz Picabia publicó en 1920 el "Manifiesto caníbal dadá". Este texto es una diatriba contra la burguesía y su "seriedad", que se concentra en el dinero: "Él es Dios, aquel que se respeta, personaje serio el dinero, respeto de las familias. Honra, honra al dinero; el hombre que posee dinero es un hombre honrado" (Picabia 19). El manifiesto de Picabia era corto e irreverente, con la misma actitud desafiadora e iconoclasta de otras manifestaciones anteriores de vanguardia, como el texto publicado en 1912 por los cubofuturistas rusos, Burliuk, Kruchënik, Maiakóvski y Khlebnikov, "Una bofetada al gusto del público". Pero, mientras este texto arremetía contra la tradición literaria, el manifiesto de Picabia se enfrentaba a otra entidad reconocida como enemiga del artista moderno: la mentalidad burguesa. Tal actitud se aproxima a aquella que se revela en la "Oda al burgués", poema "diatriba" de Mário de Andrade, publicado en Pauliceia Desvairada en 1922, y que comienza definiendo aquello que merece ser despreciado:

¡Yo insulto al burgués! El burgués-níquel,

¡el burgués-burgués!

¡La digestión bien-hecha de São Paulo!

¡El hombre-curva! ¡El hombre-nalgas!

¡El hombre que siendo francés, brasileño, italiano,

es siempre un cauteloso poco-a-poco!

Estableciendo un distanciamiento crítico con relación a las tomas de posición de ese tipo, Oswald de Andrade hizo un epitafio de las actitudes vanguardistas que guiaron la primera generación modernista, motivado por su adhesión al marxismo, y observó ácidamente que: 
La situación "revolucionaria" de esta mierda mental suramericana se presentaba así: lo contrario del burgués no era el proletario, ¡era el bohemio! Las masas, ignoradas en el territorio y como hoy, bajo la completa podredumbre económica de los políticos y de los ricos. Los intelectuales jugando a la rueda. (89)

En este fragmento del prefacio de Serafim Ponte-Grande, publicado en 1933, Oswald se incluye dentro de los intelectuales que hicieron el papel de "payaso de clase". Se refiere al "sarampión antropofágico" y a su propia novela que, contradictoriamente, publicaba entonces como ejemplo de un conjunto de actitudes poco consistentes de la intelectualidad modernista frente a la realidad brasileña.

El "Manifiesto antropófago" de 1928, con el primer aforismo lapidario que será desarrollado en varias de las consideraciones que lo suceden, instituye un "nosotros" en nombre del cual se habla: "Solo la antropofagia nos une. Socialmente. Económicamente. Filosóficamente" (en Teles 497). Se incluye, de ese modo, en la preocupación recurrente en la producción intelectual brasileña por definir el país, y dialoga con las síntesis explicativas elaboradas en obras como Retrato do Brasil, de Paulo Prado, publicado en mismo año de 1928. Y si esta obra tiene como subtítulo "ensayo sobre la tristeza brasileña", el "Manifiesto" de Oswald afirma: "la alegría es la prueba de los nueve" (en Teles 505).

La pretensión de Oswald es partir de un concepto suficientemente amplio que sea útil a la comprensión de diferentes dimensiones de una realidad que, como se deduce, es la de la nacionalidad brasileña. La perspectiva adoptada procura amalgamar las diferencias regionales o sociales de aquello que abarca la "brasilidad", así como las transformaciones históricas, y definir un solo principio que las rige: la antropofagia. Privilegia, por lo tanto, el punto de vista antropológico sobre el histórico. Se trata, con esto, de un panel interpretativo de la nación y de su pueblo.

La propuesta enunciada por Oswald de definir "lo que somos" o "lo que nos une" a través de la metáfora antropófaga, según João Almino implica que esas definiciones sobre la "brasilidad" se dan a partir del otro, mas no desde una posición subalterna:

Se concluye que la cultura brasileña no es, por tanto, insular y volcada únicamente hacia sus raíces, hacia el suelo nacional, como la lectura superficial de otros pasajes del "Manifiesto" no permitía entender, ni, por otro lado, si incidía de forma secundaria o subordinada en una civilización universal centrada en Europa. Está no solo abierta al otro, sino preparada para devorarlo. (55)

Del conjunto del "Manifiesto" se interpreta el propósito de legitimar los procesos de incorporación de las culturas extranjeras como una opción intuitiva 
desarrollada en el país, y apunta míticamente hacia su origen en la actitud de los salvajes autóctonos frente de los invasores europeos. Disminuye o se diluye, con esto, el papel desempeñado en estos procesos por diferentes tipos de violencia: por la imposición compulsiva de formas de comportamiento o del uso de la lengua europea; por el silenciamiento de las culturas locales, a través de las prohibiciones de sus manifestaciones o del desestímulo a su difusión; por la catequesis promovida con el filo de la espada, etc. En cuanto a esta, el "Manifiesto" divulga una imagen cómica del esfuerzo sistemático desprendido en la catequización y de su eficacia, incluso hasta provocar el sincretismo, pues cubre la represión violenta de manifestaciones religiosas ocurrida en diferentes momentos, que exigió disfrazar o marginar algunas expresiones, como en el caso del candomblé. En este sentido, afirma: "Nunca fuimos catequizados. Vivimos a través de un derecho sonámbulo. Hicimos a Cristo nacer en Bahía. O en Belém do Pará" (en Teles 499).

La tematización de la antropofagia en el "Manifiesto" de Oswald remitiría, de inmediato, a la mitificación del primitivismo y a la búsqueda de una autenticidad perdida que venía revelándose en el pensamiento europeo desde fines del siglo XIX, conforme observa Walter Benjamin: "Desde el final del siglo pasado [XIX], la filosofía venía realizando una serie de tentativas para aproximarse a la 'verdadera' experiencia, en oposición a aquella que se manifiesta en la vida normativizada, desnaturalizada de las masas civilizadas" (104).

En el "Manifiesto", Oswald establecería un eslabón de continuidad con esa preocupación y, aún más, con una hilera de predecesores que, a través de la metáfora de la antropofagia, borraron con un gesto de rechazo todos los discursos que concebían la racionalidad como principio único de planificación de la sociedad y de la conducción de la vida personal. Observa Benedito Nunes, citando a Heitor Martins, que "la imagen caníbal estaba en el aire". Y agrega:

Por esto, quien se aventure a establecer los antecedentes literarios privilegiados que ella tuvo será obligado a retroceder de autor en autor, indefinidamente. Esa imagen, que a ningún autor perteneció, hizo parte del repertorio común a todos, y a todos sirvió, de acuerdo con las intenciones específicas de cada cual. (15)

En esa coincidencia de la imagen de la antropofagia, Benedito Nunes recuerda las apropiaciones de esta entre artistas y pensadores, como Sigmund Freud, que en Tótem y tabú, publicado en 1912, vincula procedimientos de expiación por el parricidio inaugurador del orden simbólico a la antropofagia ritual, y asocia la necesidad de expiación de esa culpa familiar al ritual de la comunión 
instituido por el cristianismo. Es importante destacar, sin embargo, que la evocación de la barbarie o de una etapa anterior a la que se tornó convención llamar "civilización", en muchas de esas formulaciones no significaba el desprecio al progreso técnico, conforme observa Benedito Nunes:

La fuente de la "antropofagia literaria" manaba, pues, de ese territorio primitivo, que recubre todos los territorios geográfico-políticos, y con el cual la civilización técnica venía de encontrarse. [...] Comenzaba, entonces, ese diálogo, que hasta hoy continúa, entre el pensamiento lógico y el "pensamiento salvaje", a cuyo desarrollo se debe, en parte, el tremendo autoanálisis del hombre contemporáneo, que se dilacera a sí mismo, dilacerando sus mitos. (19)

Según Benedito Nunes, el diálogo constante de Oswald de Andrade con esas sugerencias y perspectivas que se destacaban en la vida cultural europea, teniendo como soporte a París, no implicaba una absorción acrítica por parte del escritor brasileño. Y la metáfora de la antropofagia era sometida a desarrollos particulares, conforme los autores y las corrientes en que surgía: "a todos sirvió, de acuerdo con las intenciones específicas de cada cual" (Nunes 15). Había en esas apropiaciones un punto común: el llamado a que se retomasen puntos de vista y modos de vivir identificados como "primitivos", que fueron reprimidos por la llegada de la civilización técnica. Esta debería continuar desarrollándose a partir de esas perspectivas volcadas hacia una realización más completa del ser humano. Los modernistas brasileños incorporaron esas propuestas y crearon versiones originales de ellas:

Asume ese nuevo primitivismo la visión pura del cubismo, la imagination sans fil del futurismo -que coincidía con la idea del salvajismo técnico de Keyserling-, la agresividad dadaísta y la libre asociación programática del surrealismo, que aprovechó conscientemente la exploración freudiana del inconsciente. Nuestro primitivismo modernista, que se corresponde con esas tendencias de las vanguardias europeas, no reedita ninguna de sus especies. (Nunes 24)

En Brasil se mantuvo en las décadas siguientes la polémica sobre el contenido de la aproximación de los modernistas a las ideas europeas, la alegada posibilidad de que se aclimataran a la realidad brasileña sin incurrir en modismos o en la sumisión a modelos poco adecuados a los contextos periféricos. Esa cuestión se transformó en un punto de roce con los escritores revelados en la "segunda generación modernista" y provocó actitudes como las de Graciliano Ramos, quien rechazó ser identificado como "modernista". En entrevista con 
Homero Senna, frente la pregunta " ¿Y qué impresión le quedó del modernismo?", Graciliano responde: "Muy mala. Siempre creí que aquello era una trampa deshonesta. Salvo rarísimas excepciones, los modernistas brasileños eran unos arrogantes. Mientras que otros procuraban estudiar alguna cosa, ver, sentir, ellos importaban a Marinetti" (Senna 50).

Rebatiendo puntos de vista como los de Graciliano Ramos, Néstor García Canclini llama la atención a una perspectiva más amplia que acompañó la incorporación de contribuciones extranjeras a la producción de los artistas latinoamericanos en la primera mitad del siglo XX:

No se trata de un trasplante, sobre todo en los principales artistas plásticos y escritores, sino de reelaboraciones deseosas de contribuir a la transformación social. Mas en todas las historias, los proyectos creadores individuales se tropiezan con el raquitismo de la burguesía, con la falta de un mercado artístico independiente, con el provincianismo (aun en ciudades de punta: Buenos Aires, São Paulo, Lima, México), con la dura competición con academicistas, con los herrumbres coloniales, con el indianismo y los regionalismos ingenuos. (79)

En esa evaluación, Néstor García Canclini no releva las contradicciones y exclusiones inherentes a los proyectos modernizadores implantados en la América Latina. El propio Oswald de Andrade, en el ya citado prefacio al Serafim Ponte-Grande, reconoce una inconsistencia o conducción dudosa de la simple irreverencia contra las tradiciones en el modernismo brasileño y hace su mea culpa: "De mi fundamental anarquismo surgía siempre una fuente saludable, el sarcasmo. Serví a la burguesía sin creer en ella. Como el cortesano explorado cortaba las ropas ridículas del regente" $(10)$. ¿ No estará él apuntando, con esa declaración, hacia la misma inconsistencia e irresponsabilidad que implica la tónica de la crítica de Graciliano Ramos a esa generación?

En el Oswald de Andrade convertido al marxismo vamos encontrar una autocrítica que se orienta a la diferencia entre la revuelta o el inconformismo frente al "retraso" de la patria y una toma de posición política que juzgaba más consistente, con mayor eficacia en su combate con las malezas brasileñas:

La valorización del café fue una operación imperialista. La poesía palo-Brasil también. Esto tenía que tumbar a las cornetas de la crisis. Como tumbó toda la literatura brasileña "de vanguardia", provinciana y de sospecha, cuando no extremadamente agotada y reaccionaria. (10)

Y resume su actitud con el tono irreverente y la contundencia que marcó sus diferentes tomas de posición en su trayectoria intelectual: "yo prefiero 
simplemente declararme enojado por todo. Y poseedor de una única voluntad. Ser, al menos, payaso de la revolución proletaria" (11).

Néstor García Canclini evalúa que se preservaba, incluso en la obra de Oswald de Andrade, un compromiso del proyecto de los modernistas latinoamericanos con la construcción de la identidad nacional:

En varios casos, el modernismo cultural, en vez de ser desnacionalizador, ha dado el impulso y el repertorio de símbolos para la construcción de la identidad nacional. La preocupación más intensa por la "brasilianidad" comienza con las vanguardias de los años veinte. "Solo seremos modernos si somos nacionales", parece ser su consigna, dice Renato Ortiz. De Oswald de Andrade a la construcción de Brasilia, la lucha por la modernización fue un movimiento por levantar críticamente una nación opuesta a lo que querían las fuerzas oligarcas y conservadoras y los dominadores externos. (78)

Este comentario no tiene en cuenta las polémicas a las que fue sometida esa cuestión en la trayectoria de los modernistas, como Oswald y Mário de Andrade, en sus conflictos con los verde-amarillistas y en las aproximaciones con el internacionalismo del marxismo o en las orientaciones hacia el posicionamiento en cuanto al nacionalismo del Partido Comunista.

Se justifica que la autocrítica de Oswald, que incluye a los otros artistas vinculados a la primera generación modernista, aun con una citación nominal libertina de Mário de Andrade, en la defensa de intereses nacionales, no se sumaba a otros "nacionalismos". La adhesión al marxismo y el esfuerzo en la concretización de la revolución proletaria implicaba un vínculo internacional con la lucha del proletariado, por encima de las fronteras y los intereses nacionales. En su obra de teatro Rei da vela, la presentación de los modos en que se desenvolvía la lucha de clases en el país remite a esa perspectiva que no puede ser caracterizada simplemente como "nacionalista", como percibió el director José Celso Martinez Corrêa en los años sesenta.

\section{¿Un nuevo "sarampión antropofágico"?}

Retomar a Oswald de Andrade como una referencia en los años sesenta obedeció a afinidades con aquello que en su obra se mantuvo como un soplo de rebeldía e irreverencia, que encajan con la antropofagia y que sobrepasan sus tomas de posición en cuanto al marxismo o los diferentes sistemas filosóficos. En la decisión del grupo Oficina de poner en escena la obra el Rei da vela, Fernando Peixoto reconoce ese potencial corrosivo de Oswald, aun cuando se revelaba confuso ideológicamente: "Al buscar a Oswald de Andrade, no 
buscamos el simple y anárquico vanguardista, sino al Oswald revolucionario, permanentemente sincero, aunque a veces confuso e ingenuo, siempre impulsado por un saludable espíritu de demolición de mitos y vacas sagradas" ("A arte numa roda viva" 173 ).

La estética adoptada en el primer montaje de esa obra, ocurrido en los años sesenta, representaba una reacción a la confusión que reinaba entre artistas e intelectuales de izquierda en Brasil después del golpe militar de 1964. En el artículo no firmado, titulado "A arte numa roda viva" y con el subtítulo "As marcas de la inocência perdida", publicado en la revista Visão en marzo de 1968, se realiza una evaluación de los problemas que se presentaban para la intelectualidad y para la clase artística que se posicionaba críticamente frente a la dictadura militar instaurada. En un análisis que recalca la desorientación generalizada, se afirma:

Los artistas que piensan que algo debe ser hecho muchas veces se irritan con la pasividad del espectador y procuran sacudirlo; solo que no siempre le saben decir para qué. Están inseguros, pues no saben si es hora de hacer la revolución, si es hora de la composición, si es hora de ayudar a la burguesía nacional, si deben luchar por el nacionalismo, por la reforma agraria. ("A arte numa roda viva" 175)

Y sigue, tomando partido por el énfasis que debía ser dado al alcance internacional que lograba la formulación de políticas en varios ámbitos desde entonces:

Se debaten en una tentativa de descubrimiento del Brasil e intentan aferrarse a veces a una tentativa de vuelta a los orígenes, en un momento en que la internacionalización se torna cada vez más una contingencia económica, sociológica y política inexorable, especialmente en el plano de las grandes decisiones (hoy los asuntos transcendentales no son tratados aisladamente por los países: existen la ONU, la FAO, la OTAN, la OEA, la UNCTAD, el Pacto de Varsovia, la Unesco, etc.). (175)

Un aspecto de interés en los fragmentos citados arriba es la revelación del tipo de discusiones que estaban en el orden del día para las izquierdas en ese periodo decisivo de la historia, después de cuatro años de dictadura militar. Entre los tópicos priorizados se encontraba el análisis de las condiciones para la implantación del socialismo, para la eclosión de la revolución. Tal vez no hubiera tanta desorientación entre los intelectuales y los artistas a finales de los sesenta, como lo indicaba quien redactó el texto citado. Por lo que se puede deducir de diferentes fuentes disponibles sobre la época, incluso del conjunto 
de la producción artístico-cultural, sería más exacto caracterizar el choque de posiciones divergentes que daba la tónica a la vida intelectual de la época. Los artistas e intelectuales de izquierdas se alineaban en dos posiciones principales alrededor de diversas cuestiones, como la concepción del nacionalismo, que se tornaban estratégicas para la formulación de propuestas políticas de resistencia a la dictadura y reconstrucción de la sociedad brasileña sobre nuevas bases. De un lado, se defendía la necesidad de una mayor madurez de la sociedad brasileña para crear un terreno propicio a la revolución socialista, a través de una alianza con las fuerzas "progresistas" de diversos matices ideológicos que se alineaban con el combate al "atraso" del país. De otro lado, algunos grupos considerados como "radicales" caracterizaban esas propuestas como "etapistas" y las acusaban de retrasar la dinámica de las luchas populares que garantizarían las condiciones para la revolución, independientemente del nivel alcanzado por el desarrollo del capitalismo local -como había ocurrido en Rusia y en China-. Muchas polémicas sobre los rumbos de la producción cultural en los años sesenta y, en especial, entre el golpe militar (1964) y el decreto del Acto Institucional n. 5 (1968), que imponía más límites democráticos al país, han tenido como telón de fondo las divergencias de alineamiento político en la izquierda brasileña. Este problema ha sido tratado, por ejemplo, por Denis Moraes (2000), en la bibliografía de Oduvaldo Vianna Filho.

El Partido Comunista continuaba ejerciendo gran influencia en la conducción de las prácticas políticas y culturales comprometidas con la oposición al régimen, y defendía una perspectiva "etapista" para las transformaciones de la sociedad brasileña. El proceso de superación del "retraso" del país implicaba la participación de sectores de la burguesía nacional, conforme la perspectiva desarrollista planteada por la declaración del comité central del Partido Comunista, en 1958, y reafirmada en el V Congreso de 1960 (Pereira 172).

El montaje de José Celso del Rei da vela, con base en una representación del Brasil como un "cadáver gangrenado", corresponde al desencanto con las políticas apoyadas por esas tesis, que defendían la alianza entre diferentes fuerzas modernizadoras, incluso sectores de la burguesía, en nombre del progreso. José Celso retomaba en los años sesenta la crítica de Oswald de Andrade, elaborada durante la era Vargas, de la continuidad en la historia brasileña de una gran "conspiración" para la perpetuación de las mismas élites en el poder y garantizar sus patrañas con intereses internacionales. En el mismo manifiesto del Oficina, en el que José Celso explica la perspectiva que dirigió su montaje del Rei da vela, ataca cualquier interpretación que procure "salvar" la historia del país a partir de una dinámica de progreso o gradual conquista de la emancipación de 
las grandes masas oprimidas, al afirmar: "Historia no hay. Hay representación. Mucho cinismo por nada" (Corrêa 50).

La adaptación de la obra de Oswald de Andrade por José Celso tuvo, entre otros motivos para provocar polémicas, ese carácter político que acompañaba la radicalización de las posiciones de izquierda. Irónicamente, utilizó un texto del autor elaborado durante el periodo en que estaba afiliado al Partido Comunista para combatir las tesis defendidas por esta fuerza política treinta años después. No dejó, sin embargo, de provocar reacciones negativas el tono bromista y la mezcla de estilos, que, sin embargo, el propio texto dramatúrgico pronosticaba, al indicar que las escenas eran próximas al circo, a la ópera y al teatro de revista. El énfasis en la irreverencia con que trataba a la cultura nacional fue uno de los aspectos recalcados por Caetano Veloso para situar la identificación del montaje con el movimiento tropicalista, que surgía en ese momento, como se puede deducir de la entrevista concedida a Augusto de Campos en 1968 por el cantautor:

Permanezco enamorado por sentir, dentro de la obra de Oswald, un movimiento que tiene la violencia que me gustaría tener contra el estancamiento, contra la seriedad. Es fácil que usted comprenda cómo Oswald de Andrade debe ser importante para mí, habiendo pasado por ese proceso, permaneciendo enamorado por una cierta broma frente a la manía de seriedad en que cayó la BN [bossa nova]. Usted sabe, yo compuse Tropicália una semana antes de ver el Rei da vela, la primera cosa que conocí de Oswald. Otra importancia muy grande de Oswald para mí es la de aclarar ciertas cosas, de darme argumentos nuevos para discutir y para continuar creando, para conocer mejor mi propia posición. Todas aquellas ideas de él sobre poesía palo-Brasil, antropofagismo, realmente ofrecen argumentos actuales que son nuevos incluso frente a aquello que se estableció como nuevo. ("Conversa")

El montaje del Rei da vela para Caetano Veloso, por tanto, sirvió para traer combustible intelectual a su propuesta de sacar la música popular de la "seriedad en que cayó la BN (bossa nova)" y, ciertamente, de su compromiso con el "buen gusto", alcanzado como un híbrido de la samba y del cool jazz norteamericano. Caetano Veloso reconoce en Oswald de Andrade "un movimiento que tiene la violencia que me gustaría tener contra el estancamiento, contra la seriedad". Esa irreverencia les permitió a él y a otras figuras asociadas al movimiento llevar a la música consumida por un público de formación universitaria otros géneros, considerados "populares", "de masa" o "pobres culturalmente". Posibilitó acercar, rompiendo jerarquías, las canciones de suceso en la industria cultural, la música nordestina de circulación local y el rock'n roll. En 1967, la presentación de la 
canción Alegría, alegría por Caetano Veloso, acompañado por el conjunto Beat Boys, y la de Gilberto Gil, con la música Domingo en parque, que traía el ritmo de capoeira acompañada por los roqueros de Os Mutantes en el III Festival de la Música Popular (TV Record), marcaron una toma de posición y un desafío a la campaña contra el uso de la guitarra eléctrica en la música popular brasileña. Gilberto Gil había participado pocos días antes de esa toma de posición en la marcha contra el uso de la guitarra eléctrica y la influencia de la música norteamericana, lo que reforzaba la versión sobre la confusión de concepciones que reinaba en la época. Esta marcha empeoró la división entre la llamada "joven guardia" y los herederos de la bossa nova que se destacaban en la canción de protesta.

La actitud de los músicos y letristas involucrados con el movimiento tropicalista, en especial Caetano Veloso, Gilberto Gil y Tom Zé, se relacionaba con la estética pop. Compartían con esa vertiente del arte contemporáneo el desdén por la obligación de llevar un mensaje de alineamiento político claro. El inventario de aspectos que aproximaban esos movimientos era complementado por: la fusión de elementos de procedencias culturales distintos en una misma obra; el acercamiento al dadaísmo en el gusto por el ready-made, por lo inusitado del lenguaje verbal y musical, como también por las performances sorprendentes; y el coqueteo con la industria cultural. Los arreglos musicales del maestro Rogério Duprat acentuaban esos rasgos presentes en las letras, en la melodía y en la presentación pública de las canciones. Uno de los ejemplos elocuentes de esa mezcla es la canción "Geléia geral" ("Jalea general"), una especie de manifiesto explicativo de esa posición irreverente de los tropicalistas. El arreglo de la canción, en la grabación divulgada en el antológico disco Panis et circenses, exhibe, como varias otras, el hibridismo de referencias culturales: la canción, con una cadencia que recuerda la música nordestina, se inicia con una especie de llamada o abertura con acordes de guitarra eléctrica. La canción, de Torquato Neto y Gilberto Gil, retrata "la jalea general brasileña que el periódico fornal do Brasil anuncia". El estribillo "Y bumba-ye-ye-boye año que viene mes que fue. / Y, bumba-ye-ye-ye es la misma danza, mi boye" refuerza el rechazo del movimiento a tener que elegir entre la tradición de la cultura nacional y la moda importada, el llamado ye-ye-ye. En una de las estrofas, se define la "danza" antropofágica que caracteriza el país y de la cual quien no participa "no habla, asiste a todo y se calla". Se observa en esa caracterización muchos de los elementos definidores de la estética tropicalista y del modo en que hace un retrato del Brasil:

Es la misma danza en la sala, en Canecão, en la TV.

Y quien no danza no habla, asiste a todo y se calla.

No ve en medio de la sala las reliquias del Brasil: 
dulce mulata malvada, un LP de Sinatra, maracuyá, mes de abril, santo barroco bahiano, súperpoder de paisano, formiplac y cielo de añil. Tres destaques de la Portela, carne seca en la ventana, alguien que llora por mí. Un carnaval de verdad, hospitalaria amistad, brutalidad y jardín.

Se definen "las reliquias del Brasil" con clichés que integran el sentido común ("dulce mulata malvada"), con elementos de la cultura $p o p$ internacional de origen norteamericano ("un LP de Sinatra"), la marca de un producto industrial, la placa de fórmica propia de la cotidianidad del brasileño de todas las clases sociales y cuadrantes regionales ("formiplac"), junto a elementos de la cultura popular y características particulares descritas por la convención o con una dimensión crítica ("hospitalaria amistad, brutalidad y jardín").

Regreso a un punto destacado anteriormente en este trabajo: el movimiento tropicalista, a través de la letra, de la sonoridad y de la performance de los músicos -que se parecía a la de los roqueros estadounidenses, principalmente de aquellos que encajaban con la ola hippie-, atacaba la preocupación nacionalista y la gestualidad próxima a los oradores de los comicios políticos que dominaban en la canción de protesta. Esa confrontación consistía en una disputa sobre las representaciones del país y en una evaluación sobre la eficacia de las luchas emprendidas para la modificación de la realidad, que ambas tendencias consideraban marcada por el tradicionalismo. Coincidían, además, en la perspectiva sobre el "retraso" del país. En cuanto a las tendencias que se aproximan al movimiento tropicalista, cabe recalcar la agresividad en la estética adjudicada por José Celso Martinez Corrêa a los espectáculos del grupo Oficina, posteriores al Rei da vela, que parecían más próximos a una provocación, a un desafío a la adhesión a formas de lucha política más radicales que las que emplearon los "conspiradores" contra la burguesía nacional, sobre los cuales manifestaba su desprecio desde entonces.

\section{La antropofagia periférica}

Una de las cuestiones que se presenta desde el inicio sobre el rescate de la metáfora antropofágica por el poeta Sérgio Vaz, en el "Manifiesto de la antropofagia periférica", divulgado inicialmente en la Semana de Arte Moderno de la Periferia en 2007, es la del alcance que pretende darle. Así se abre el "Manifiesto": "La periferia nos une por el amor, por el dolor y por el color". ¿Qué implicaciones tiene la sustitución que realizó de la palabra antropofagia, contenida en la apertura del "Manifiesto" de Oswald de Andrade, por periferia? ¿A qué ámbito de problemas se refiere con el uso de la primera persona del plural al comienzo 
del "Manifiesto"? ¿Será un uso semejante al de Oswald de Andrade? Observé en este trabajo que la metáfora sirve para explicar un rasgo singular que el escritor atribuye a la vida cultural en Brasil, sin hacer precisiones sobre la inmensidad y la diversidad del territorio del país y sobre las diferencias determinadas por el paso de la historia. Por tanto, adopta una perspectiva antropológica.

En el caso de Sérgio Vaz, la dimensión antropológica se sustituye por una aproximación de naturaleza sociológica: el manifiesto se refiere de entrada a la periferia. Con esto, se plantea la duda, pues se pretende caracterizar las propuestas de un "nosotros" que no tiene más la dimensión nacional. Esa reducción del foco se refuerza por la alusión al "dolor" y al "color". El segundo verso define de dónde deberá partir "la voz que grita contra el silencio que nos castiga": esa voz vendrá, según el poeta, de los "callejones y paseos"; por tanto, de los espacios de exclusión social.

Con base en estos datos del inicio del "Manifiesto", se puede comprender que se trata del anuncio o de una llamada para que se cumpla una promesa que pretende redimir el país de una falta que se mantiene en la historia nacional. Así, se abre el horizonte al que se refiere el mensaje y la audiencia a la que se destina: "He aquí que surge de las laderas un pueblo lindo e inteligente galopando contra el pasado. A favor de un suburbio que clama por arte y cultura, y universidad para la diversidad. Agogôs y tamborins acompañados de violines, solo después de la clase" (Vaz 50). Las imágenes sugieren, por tanto, un movimiento que, a partir de la periferia, venga a sanear el país, a contribuir para que sean sobrepasadas las viejas malezas históricas.

El "Manifiesto" de Vaz se fundamenta en otras prácticas que el escritor desarrolla en la periferia de São Paulo, los saraos de la Cooperación Cultural de la Periferia (Cooperifa). Divulga la perspectiva que impulsa su actuación de promotor de la cultura en la periferia, demarcando algunos principios y límites de actuación: "Contra el artista servicial esclavo de la vanidad. Contra los vampiros de las palabras públicas y el arte privado. / El arte que libera no puede venir de la mano que esclaviza. Por una periferia que nos une por el amor, por el dolor y por el color" (Vaz 51).El escritor concibe la redención del país teniendo como instrumentos el arte y la cultura, según se observa en varios fragmentos, como el siguiente:

Es preciso chupar del arte un nuevo tipo de artista: el artista-ciudadano. Aquel que en su arte no revoluciona el mundo, pero tampoco hace pactos con la mediocridad que idiotiza a un pueblo desproveído de oportunidades. Un artista al servicio de la comunidad, del país. Que, armado con la verdad, por sí solo ejercita la revolución. (51) 
En estas formulaciones de propuestas y de principios que guían la acción transformadora a ser emprendida, con la alusión a la antropofagia, se observa una sobrevaloración del papel del arte y del artista y de su autonomía, que evoca las concepciones románticas. Esa posición se refleja también en los elogios al papel de la lectura y es reforzada en algunas de las crónicas del libro en el que es publicado el "Manifiesto". Surge de modo más claro en los aforismos, incluidos en estos textos o en páginas intermedias del volumen, como los siguientes: "iQuien lee ve mejor!" (49) o "El artista es la última línea de la sociedad, cuando él desiste es porque no resta más nada" (63).

El "Manifiesto de la antropofagia periférica" reivindica la posibilidad de la población de la periferia de realizar elecciones sobre el tipo de cultura a la que desea tener acceso para ejercer el papel histórico que le está reservado, sin marcar una posición muy clara sobre las tradiciones culturales o las vertientes de la producción actual que deben o no ser "deglutidas". Coherente con esa postura sobre las posibilidades de elección, las convenciones literarias no son cuestionadas, pues parece que todas son bienvenidas como productos de "cultura".

Queda clara, al menos en las declaraciones de Sérgio Vaz, una vinculación de la literatura periférica con el hip-hop, lo que puede ser constatado en un fragmento del debate de la profesora Heloísa Buarque de Holanda con Sérgio Vaz, relatado por la investigadora Érica del Nascimento. El diálogo aborda también la cuestión de la legitimación cultural o el reconocimiento de la producción periférica como literatura:

Heloísa Buarque preguntó a Sérgio Vaz si la clasificación "literatura hip hop" tampoco sería pertinente, teniendo en cuenta que la actitud de los escritores se asemeja a de los rappers. E indagó si el cuestionamiento sobre si es o no literatura lo que producen no es una provocación política. En cuanto al primer alegato, Sérgio Vaz responde que la literatura periférica debe todo al hip hop porque fue ese movimiento el que mostró que la favela no está tan mal articulada. Con relación a la segunda, el poeta dijo que deja para los estudiosos decidir si es o no literatura. Él lo considera literatura, pero como una literatura diferente, con menos guion y punto y coma. (Nascimento 144)

La aproximación de esa literatura con el hip hop puede ser considerada por la cuestión "performática" involucrada en ambas manifestaciones. Vale recordar que los textos destinados u oriundos de los saraos pierden mucho de su vigor cuando son reproducidos en papel. Algo semejante ocurre con los textos de los rappers que, como declaró Nelson Maca, también rapper y profesor universitario, desafían la capacidad de aquel que intenta registrarlos por escrito: 
Cuando asumí la tarea de organizar los originales de A rima denuncia [libro del rapper Gog] ya había experimentado, en trabajos similares, el gran desafío de transcribir una obra sonora, musical, para el formato silencioso de las páginas impresas. [...] No fue tarea fácil localizar el ritmo propicio para cada uno de los muchos versos del libro. La inflexión de la voz, los diálogos entre los intérpretes, las citaciones y collages musicales hechos por el productor musical, los elementos de sonoplastia, la técnica de respiración y, en el caso de videoclips y presentaciones, hasta el movimiento del cuerpo son elementos que dan significación al rap. (Gonçalves 244-245)

Nelson Maca, quien se encargó de la transcripción de las creaciones del rapper Genival Oliveira Gonçalves (Gog), revela que en ese proceso se pierde la colaboración del ritmo de la percusión, del cuerpo del intérprete, y agrega incluso el estado de ánimo de la audiencia presente para la cual la obra fue elaborada. La falta de estos elementos en el paso a la escritura remite a los estudios desarrollados por Paulo Zumthor sobre poesía y oralidad.

La publicación de un libro como Literatura, pão e poesia, de Sérgio Vaz, con el sello de la crítica universitaria, así como con la oportunidad de ser producido y distribuido en una editorial con solidez y alcance en el mercado, pone en marcha los mecanismos convencionales de evaluación para los productos que integran ese tipo de circuito. Tal vez esas circunstancias estén relacionadas con la predominancia, en el libro Literatura, pão e poesia, de textos que se limitan a las convenciones habituales de la crónica sobre lo cotidiano o de consejos. No se revela la actitud de desafío presente en las manifestaciones de la cultura hip hop, la tentativa de encontrar modos de expresión particulares y puestos en ángulos de la experiencia periférica diferentes de aquellas presentadas por los medios o comprometidas con el sentido común, y, por tanto, capaces de reproducir o acomodarse a los clichés y preconceptos dirigidos a las comunidades marginadas.

En cuanto a las actitudes contradictorias de la aproximación de Sérgio Vaz a los medios y a la academia, y su rechazo a reconocer la búsqueda de reconocimiento externo de la producción periférica, cabe recordar la ambigüedad de la relación con las instancias de legitimación artística que acompaña, desde hace mucho, a las corrientes, los movimientos y los individuos que pretenden romper, de algún modo, con los cánones artísticos. Esta situación es revelada por las actitudes contestatarias de Charles Baudelaire, en cuanto a su tentativa de ingresar a la Academia Francesa. Este conflicto es estudiado por Pierre Bourdieu (en Kehl 287-290).

Una cuestión que interfiere en el debate sobre la producción textual relacionada con los saraos de periferia es que ejerce funciones en la vida comunitaria 
que superan las que son habitualmente desempeñadas por la literatura escrita. Está ligada a la promoción de la autoestima de los participantes, al estímulo de actividades culturales nacidas en la propia comunidad, incluso con finalidad comercial. Por esto, suscita un gran interés de antropólogos como Érica del Nascimento, quien recuerda las observaciones de Silviano Santiago (1998) sobre los estudios de otro antropólogo, Carlos Alberto Messeder Pereira, con relación a la literatura marginal de los años setenta. Viene de esa transformación de las funciones de la literatura la necesidad de discutir lo que representa su publicación en libro y su divulgación en gran escala: ¿un retroceso?, ¿el empobrecimiento del desafío a las condiciones de producción que representó en su aparición? o ¿una tentativa de apertura de fronteras con la afirmación de una nueva vertiente de la cultura en un escenario más amplio?

Frente al proceso de renovación constante, motivado por las luchas en búsqueda de la legitimación cultural dentro y fuera del campo literario, es importante preservar la libertad del antropófago de escoger su comida, pero sin confundirla con un llamado a que se suspenda cualquier posibilidad de análisis o comentario que no sea un elogio a la habilidad en la composición de sus platos. Por esto, no acepto que debamos adoptar sin crítica el aforismo publicado por Sérgio Vaz en su libro: "El arte no se explica. O usted entiende o se identifica" (69).

\section{Obras citadas}

"A arte numa roda viva: as marcas da inocência perdida". Visão (1. ${ }^{\circ}$ de marzo de 1968). Reportaje reimpreso en Revista Dionysos (MEC/SNT) 26 (1982): 32-39.

Almino, João. "Por um universalismo descentrado: considerações sobre a metáfora antropófoga". Eds. João Cezar de Castro Rocha y Jorge Ruffinelli. Antropofagia Hoje? : Oswald em cena. São Paulo: É Realizações, 2011. 15-27.

Andrade, Mário de. "Ode ao burguês". 1912.

Web. <http://www.culturabrasil.pro.br/burgues.htm>.

Andrade, Oswald de. Serafim Ponte Grande. São Paulo: Global, 1985.

Benjamin, Walter. Obras escolhidas III. Charles Baudelaire um lírico no auge do Capitalismo. Trads. José Martins Barbosa y Hemerson Alves Baptista. São Paulo: Brasiliense, 1989.

"Conversa com Caetano Veloso". Balanço da Bossa e outras bossas.

São Paulo: Perspectiva, 1968. Web. <http://tropicalia.com.br/

eubioticamente-atraidos/verbo-tropicalista/conversa-com-caetano>.

Corrêa,José Celso Martinez. "O rei da vela: manifesto do oficina".

Revista Dionysos 26 (1967): 45-52. Ministério da Educação e

Cultura, Serviço Nacional de Teatro. Janeiro de 1926. 
García Canclini, Néstor. Culturas híbridas: estratégias para entrar e sair da modernidade. Trads. Ana Regina Lessa y Heloísa Pezza Cintrão. São Paulo: EDUSP, 1998.

Gonçalves, Genival Oliveira. A rima denuncia. São Paulo: Global, 2013.

Kehl, Maria Rita. Ressentimento. São Paulo: Casa do Psicólogo, 2011.

Moraes, Dênis de. Vianinha, cúmplice da paixão. Río de Janeiro: Record, 2000.

Nascimento, Érica Peçanha do. "É tudo nosso! Produção cultural na periferia paulistana". Tesis. Programa de Posgrado en Antropología Social, Facultad de Letras, Filosofía y Ciencias HUmnas (FFLCH), Universidade de São Paulo, 2011.

Nunes, Benedito. Oswald canibal. São Paulo: Perspectiva, 1979.

Picabia, Franz. Manifiesto caníbal dadá (1920). Barcelona: Seix Barral, 1977.

Pereira, Victor Hugo Adler. "O rei e as revoluções possíveis". Ed. Gilberto Mendonça Teles. Oswald plural. Río de Janeiro: EDUERJ, 1995 • 163-181.

Santiago, Silviano. "Democratização no Brasil, 1979-1981 (cultura versus arte)". Ed. Raúl Antelo. Declínio da arte, ascensão da cultura.

Florianópolis: Letras Contemporâneas; Abralic, 1998. 11-23.

Senna, Homero. "Revisão do modernismo". Ed. Sônia Brayner. Graciliano Ramos. Río de Janeiro: Civilização Brasileira, 1978 . 46-59.

Teles, Gilberto Mendonça. Vanguarda europeia \& modernismo brasileiro. Río de Janeiro: José Olympio, 2012.

Vaz, Sérgio. Literatura, pão e poesia: histórias de um povo lindo e inteligente. São Paulo: Global, 2011.

Zumthor, Paul. Introdução à poesia oral. Trads. Jerusa Pires Ferreira, Maria Lúcia Diniz Pochat y Maria Inês de Almeida. Belo Horizonte: UFMG, 2010. 